\title{
Effect of Biliary Excretion on the Pharmacokinetics of Pitavastatin (NK-104) in Dogs
}

\author{
Junji KoJima, Takeshi OHshima, Michiaki YonedA and Hironobu SawadA \\ Tokyo Research Laboratories, Pharmaceutical Division, Kowa Co., Ltd., Tokyo
}

\begin{abstract}
Summary: The disposition of pitavastatin and pitavastatin lactone, which are mutually converted in the circulatory system, was investigated after intravenous administration of pitavastatin in dogs equipped with chronic bile-duct catheters.

The plasma concentration of pitavastatin declined three-exponentially after dosing in the dogs with both diverted and non-diverted bile-flow. The terminal elimination half-life $\left(\mathrm{T}_{1 / 2}\right)$ of pitavastatin in the diverted and non-diverted conditions was 3.12 and $5.01 \mathrm{hr}$, and that of pitavastatin lactone 4.50 and $7.23 \mathrm{hr}$, respectively. The diverted bile-flow decreased the $\mathrm{AUC}_{0-24 \mathrm{hr}}$ for pitavastatin and its lactone to 66 and $64 \%$, respectively.

In the dogs with the diverted bile-flow, $56.1 \%$ and $4.2 \%$ of the dose was recovered in the bile as pitavastatin and its lactone, respectively. The biliary clearance $\left(\mathrm{CL}_{\mathrm{b}}\right)$ of pitavastatin and its lactone was 32.5 and 6.8 $\mathrm{mL} / \mathrm{min}$, respectively, and the $\mathrm{CL}_{\mathrm{b}}$ of pitavastatin was about 4.8 -fold that of its lactone.

In the dogs whose bile-flow was not diverted, the cumulative biliary excretion of pitavastatin and its lactone was estimated from the $\mathrm{AUC}_{0-24} \mathrm{hr}$ and $\mathrm{CL}_{\mathrm{b}}$ of both forms of pitavastatin. The estimated amount was increased by $46 \%$ compared with that in the dogs with the diverted bile-flow. This indicates that the increase reflects the actual contribution of the enterohepatic circulation.
\end{abstract}

\section{Key words: Enterohepatic circulation, Biliary excretion, NK-104, NK-104 lactone, Chronic bile-duct cannulated dog}

\section{Introduction}

Pitavastatin, monocalcium bis $[(3 \mathrm{R}, 5 \mathrm{~S}, 6 \mathrm{E})-7-[2-\mathrm{cy}-$ clopropyl-4-(4-fluorophenyl) -3-quinolyl ]-3,5-dihydroxy-6-heptenoate], is a fully synthetic drug and a potent and selective inhibitor of $\mathrm{HMG}-\mathrm{CoA}$ reductase, the rate limiting enzyme in cholesterol biosynthesis. ${ }^{1,2)}$ In clinical trials, this agent has been reported to lower both total cholesterol and total triglyceride levels in patients with hypercholesterolemia. ${ }^{3)}$

In a preclinical study using rats, rabbits, dogs, and monkeys, pitavastatin showed good absorptivity and bioavailability (30-80\%) after oral administration in all these animals except monkeys. ${ }^{4)}$ The lactone form of pitavastatin (pitavastatin lactone) was also identified as a major metabolite in the plasma except in rats. ${ }^{4)}$ The other metabolites of pitavastatin have been examined in the bile of rat, rabbit, and dog. Pitavastatin underwent lactonization, $\beta$-oxidation of a side chain, hydroxylation of a quinoline ring, and conjugation, and produced about ten metabolites by the combination of these reactions. ${ }^{5)}$ However, pitavastatin was the predominant component of these bile samples. After intravenous administration of ${ }^{14} \mathrm{C}$ - pitavastatin in the rat, about $75 \%$ of radioactivity was excreted in the bile as unchanged pitavastatin. ${ }^{6)}$ These findings suggest that pitavastatin entered the enterohepatic circulation. However, pitavastatin lactone, which is mutually converted to pitavastatin in the cir- culatory system, could not be evaluated because it is rapidly hydrolyzed in the rat plasma.

The objectives of the present study using dogs were (a) to demonstrate the enterohepatic circulation of pitavastatin taking the contribution of pitavastatin lactone into consideration, and (b) to clarify the relation between the enterohepatic circulation and terminal elimination phase for pitavastatin and its lactone.

\section{Materials and Methods}

\section{Chemicals}

Pitavastatin, pitavastatin lactone and an internal standard, bis[(3R,5S,6E)-7-[2-isopropyl-4-(4-fluorophenyl )-3-quinolyl]-3,5-dihydroxy-6-heptenoate ], were supplied by Nissan Chemical Industry (Tokyo, Japan) (Fig. 1). The pitavastatin concentration was expressed as an anhydrous calcium salt, because pitavastatin contained about 10\% water. All other chemicals and solvents used in this study were commercial products of analytical grade. All samples were protected from light to minimize degradation.

\section{Preparation of Bile-duct Cannulated Beagles}

Three male beagles (8-15 kg body weight) were obtained from Japan Laboratory Animals (Tokyo, Japan). The animals were housed at $23 \pm 3^{\circ} \mathrm{C}$ and $50 \pm 20 \%$ relative humidity under a 12-hr light/dark cycle. The feeding of $250 \mathrm{~g}$ of solid pellet DS (Oriental Yeast, Japan)

興和株式会社 東京研究所 干189-0022 東京都東村山市野口町 2-17-43 


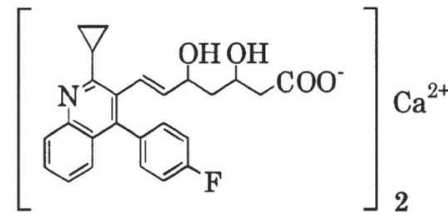

Pitavastatin

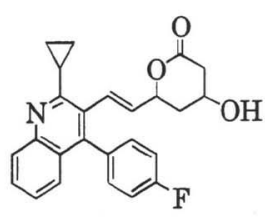

Pitavastatin lactone
Fig. 1 Structure of pitavastatin and its lactone

was done once a day and drinking water was given ad libitum.

The dogs were anesthetized with an intravenous injection of pentobarbital (30 mg/kg; Dainippon Pharmaceutical, Japan). A catheter (6Fr; Atom Medical, Japan) for bile collection was placed into the common bile-duct toward the liver and a second one toward the duodenum. A third catheter for flushing was placed into the cystic duct and then the gallbladder was carefully excised using an electric mess. The catheters were led out through a stub hole in the right flank and those on the side of the liver and duodenum were connected to produce a biliary circuit. These catheters and the connection were protected with a jacket (IAJ-03F; Ina Research, Japan). Five $\mathrm{mL}$ of Penicillin-G (40,000 units/mL; Meiji Seika, Japan) was given daily by subcutaneous injection for about seven days to prevent postsurgical infection. Moreover, Polymyxin-B ointment (Pfizer Pharmaceutical, Japan) was applied to the sutured site. The dogs were allowed to recover for at least two weeks after surgery. Flushing with physiological saline was conducted every day to clean the catheters.

\section{Drug Administration}

The bile-duct cannulated dogs $(n=3)$ were restrained in a standing position with a sling-type fixer (Alice King Chatham Medical Arts, Hawthorne, California, USA), and pitavastatin was administered intravenously to a foreleg vein at a dose of $0.1 \mathrm{mg} / \mathrm{kg}$ as a solution of physiological saline $(0.5 \mathrm{mg} / \mathrm{mL})$. For the pharmacokinetic experiments, pitavastatin was administered to each dog on two separate occasion, i.e., in the diverted and nondiverted bile-flow conditions under a random design. All dogs were fasted for at least $18 \mathrm{hr}$ prior to and $8 \mathrm{hr}$ after dosing. Water was freely available.

\section{Blood Sample and Bile Collection}

Heparinized blood samples $(2.5 \mathrm{~mL})$ were taken from the foreleg vein for $24 \mathrm{hr}$ in the diverted and non-diverted bile-flow conditions. The sampling times were 2,5 , 10, 30, and $60 \mathrm{~min}$, and 2, 3, 4, 6, 8, 12, and $24 \mathrm{hr}$ after intravenous injection. All blood samples were immediately placed on ice and centrifuged at $4^{\circ} \mathrm{C}$ to minimize the hydrolysis of pitavastatin lactone. ${ }^{7)}$ The plasma samples were frozen at $-20^{\circ} \mathrm{C}$ until analyzed.

In the dogs with the diverted bile-flow, the bile was also collected by opening the connection of the biliary circuit. All of the bile up to $24 \mathrm{hr}$ post-injection was continuously collected into an iced volumetric container, in which $10 \mathrm{~mL}$ of $1 \mathrm{M}$ potassium dihydrogen phosphate, 5 $\mathrm{mL}$ of acetonitrile, and $30 \mathrm{~mL}$ of water were previously added to dissolve and prevent hydrolysis of pitavastatin lactone. The sampling intervals were $0-10,10-20,20$ $30,30-40,40-50,50-60,60-80,80-100$, and $100-120$ min, and $2-2.5,2.5-3,3-4,4-6,6-8,8-12$, and $12-24 \mathrm{hr}$. The collected bile was diluted with water and an aliquot was frozen at $-20^{\circ} \mathrm{C}$ until analyzed. No compensation for the withdrawal of bile was made.

\section{Extraction and Quantification of Pitavastatin and its Lactone in Dog Plasma and Bile}

The plasma concentrations of pitavastatin and its lactone were determined according to the column-switching HPLC method reported previously. ${ }^{7)}$ The calibration range for the plasma samples was from 0.5 to $100 \mathrm{ng} /$ $\mathrm{mL}$.

In the case of diluted bile samples, the analysis was accomplished by the column-switching HPLC method modified to minimize interference due to the matrix by slightly changing the composition of the mobile phase. Briefly, $0.5 \mathrm{~mL}$ of the diluted bile, $1 \mathrm{~mL}$ of $1 \mathrm{M}$ potassium dihydrogen phosphate, $0.5 \mathrm{~mL}$ of water, and $0.5 \mathrm{~mL}$ of internal standard solution $(100 \mathrm{ng} / \mathrm{mL})$ were mixed. The mixture was extracted with $6.5 \mathrm{~mL}$ of tert-butyl methylether by mechanical shaking. The organic layer was transferred to another colored tube and $0.5 \mathrm{~mL}$ of diazomethane ether solution was added. After $30 \mathrm{~min}$, excess diazomethane was degraded by adding $2 \mathrm{~mL}$ of $1 \mathrm{M}$ potassium dihydrogen phosphate and by mechanical shaking. The organic layer was evaporated dry under a gentle stream of nitrogen gas. The residue was reconstituted in $200 \mu \mathrm{l}$ of $0.2 \mathrm{M}$ acetic acid-acetonitrile (1: 1, v/ v) and an aliquot was injected into the HPLC system.

The HPLC system consisted of two LC-6A pumps, an SIL-6A autosampler, a CTO-6A column oven, an SPD$6 \mathrm{~A}$ ultraviolet detector, an FCV-3AL solvent changing valve and an FCV-2AH six-port switching valve, all of which were controlled by an SCL-6A system controller (all from Shimadzu, Japan). The column-switching HPLC separation was performed with two Cosmosil$5 \mathrm{C} 18$ columns $(150 \times 4.6 \mathrm{~mm}$ I.D.; Nacalai Tesque, Japan) for the pre-separation and analytical separation. Two mobile phases, $0.2 \mathrm{M}$ ammonium acetate buffer $(\mathrm{pH} 4)$-acetonitrile $(1: 1, \mathrm{v} / \mathrm{v})$ for the pre-separation and $0.1 \mathrm{M}$ formic acid-acetonitrile $(3: 2, \mathrm{v} / \mathrm{v})$ for the analytical separation, were maintained at a flow rate of 1 $\mathrm{mL} / \mathrm{min}$. The analytes eluted from column-1 within a retention time of about $10-14 \mathrm{~min}$ were transferred to column- 2 by switching the six-port valve for $2.6 \mathrm{~min}$, and further separated with mobile phase- 2 . The detection was carried out at $250 \mathrm{~nm}$ with the ultraviolet detector. The column temperature was maintained at $40^{\circ} \mathrm{C}$.

The assay was validated and had the following specifi- 
cations: the calibration range for the bile sample, 1 to 500 $\mathrm{ng} / 0.5 \mathrm{~mL}$; the intra-day repeatability (three days, three concentrations, $n=5$ ), less than $5 \%$ for pitavastatin and less than $6 \%$ for its lactone. The extraction rate of pitavastatin and its lactone was more than 95\%. The within-batch stability of extracted sample was at least 24 $\mathrm{hr}$ at room temperature and all samples were analyzed within this period.

\section{Pharmacokinetic Analysis}

The plasma concentration time-data of pitavastatin was curve-fitted to a three-exponential equation using a nonlinear least squares program, Win Nonlin (version 1.1; Pharsight, USA). The observed plasma concentration $\left(C_{p}\right)$ data was weighed by $1 / C_{p}^{2}$. Model-independent parameters such as the plasma clearance $\left(\mathrm{CL}_{\mathrm{p}}\right)$, area under the concentration time curve up to $24 \mathrm{hr}$ $\left(\mathrm{AUC}_{0-24 \mathrm{hr}}\right), \mathrm{AUC}$ up to infinity $\left(\mathrm{AUC}_{\text {inf }}\right)$, mean residence time up to infinity $\left(\mathrm{MRT}_{\text {inf }}\right)$, steady-state volume of distribution $\left(\mathrm{V}_{\mathrm{ss}}\right)$, and elimination half life $\left(\mathrm{T}_{1 / 2}\right)$ were obtained using the function of Win Nonlin.

For the plasma concentration time-data of pitavastatin lactone, the noncompartment approach was applied. The elimination rate constant $\left(k_{\mathrm{el}}\right)$ was determined by a linear regression analysis of the log-linear portion of the terminal phase, and $T_{1 / 2}$ was calculated from $T_{1 / 2}=\ln 2 /$ $\mathrm{k}_{\mathrm{el}}$. The $\mathrm{AUC}_{0-24 \mathrm{hr}}$ was calculated from the plasma concentration up to $24 \mathrm{hr}$ by the trapezoidal rule and the $\mathrm{AUC}_{\text {inf }}$ was determined by extrapolation to infinity. ${ }^{8)}$

The bile clearance of pitavastatin and its lactone ( $\mathrm{CL}_{\mathrm{b} \text { (Pitava) }}$ and $\mathrm{CL}_{\mathrm{b} \text { (Lactone) }}$ ) was obtained from the following equations.

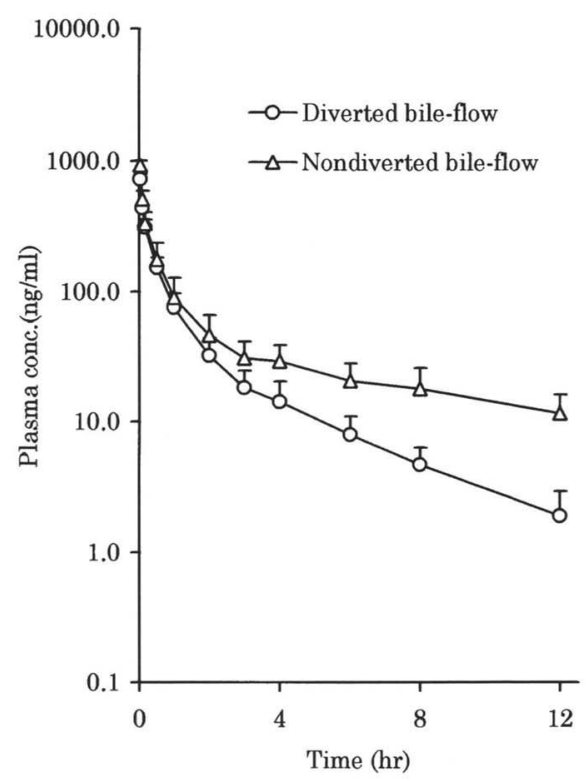

$$
\begin{aligned}
& \mathrm{CL}_{\mathrm{b}(\text { Pitava })}=\mathrm{X}_{\mathrm{b} \text { (DIVERT, Pitava) }} / \mathrm{AUC}_{0-24 \mathrm{hr} \text { (DIVERT, Pitava) }} \\
& \mathrm{CL}_{\mathrm{b} \text { (Lactone) }}=\mathrm{X}_{\mathrm{b} \text { (DIVERT, Lactone) })} / \mathrm{AUC}_{0-24} \mathrm{hr} \text { (DIVERT, Lactone) }
\end{aligned}
$$

where $\mathrm{X}_{\mathrm{b} \text { (DIVERT, Pitava) }}$ and $\mathrm{X}_{\mathrm{b} \text { (DIVERT, Lactone) }}$ are the cumulative biliary excretion of pitavastatin and its lactone, respectively, up to $24 \mathrm{hr}$ in the dogs with the

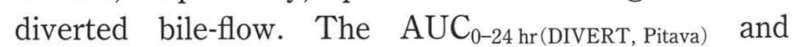
$\mathrm{AUC}_{0-24 \mathrm{hr} \text { (DIVERT, Lactone) }}$ are the values of pitavastatin and its lactone, respectively, in the diverted bile-flow condition.

On the contrary, the cumulative biliary excretion of pitavastatin and its lactone ( $\mathrm{X}_{\mathrm{b} \text { (NONDIVERT, Pitava) and }}$ $\mathrm{X}_{\mathrm{b} \text { (NONDIVERT, Pitava) }}$ ) in the non-diverted bile-flow condition were estimated from the equations.

$$
\begin{aligned}
\mathrm{X}_{\mathrm{b} \text { (NONDIVERT, Pitava) })=} & \mathrm{AUC}_{0-24 \mathrm{hr} \text { (NONDIVERT, Pitava) }} \\
& \times \mathrm{CL}_{\mathrm{b} \text { (Pitava) }} \\
\mathrm{X}_{\mathrm{b} \text { (NONDIVERT, Lactone) })} & \mathrm{AUC}_{0-24 \mathrm{hr} \text { (NONDIVERT, Lactone) }} \\
& \times \mathrm{CL}_{\mathrm{b} \text { (Lactone) }}
\end{aligned}
$$

where the $\mathrm{AUC}_{0-24 \mathrm{hr} \text { (NONDIVERT, Pitava) and }}$ $\mathrm{AUC}_{0-24 \mathrm{hr} \text { (NONDIVERT, Lactone) }}$ are the values of pitavastatin and its lactone, respectively, in the non-diverted bileflow condition.

\section{Results}

\section{Pharmacokinetic Parameters of Pitavastatin and its Lactone}

The plasma concentration-time data for pitavastatin and its lactone after intravenous administration of pitavastatin in the bile-duct cannulated dogs with the diverted and non-diverted bile-flow are shown in Fig. 2.

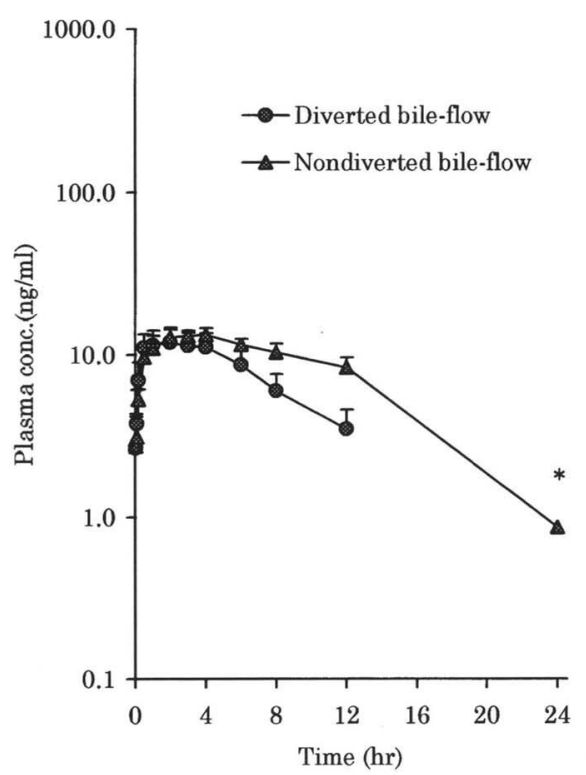

Fig. 2 Mean plasma levels of pitavastatin (left) and its lactone (right) after intravenous administration of $0.1 \mathrm{mg} / \mathrm{kg}$ of pitavastatin in the dogs with diverted and non-diverted bile-flow Each point represents the mean and S.E. of three experiments.

* ; Pitavastatin lactone was detected in two out of three experiments. 
Table I Pharmacokinetic parameters of pitavastatin and its lactone after intravenous administration of $0.1 \mathrm{mg} / \mathrm{kg}$ of pitavastatin in chronic bile-duct cannulated dogs

\begin{tabular}{|c|c|c|c|}
\hline \multirow{2}{*}{ Drug } & \multirow{2}{*}{ Parameters (unit) } & Diverted bile-flow condition & Nondiverted bile-flow condition \\
\hline & & Mean \pm S.E. & Mean \pm S.E. \\
\hline \multirow{6}{*}{ Pitavastatin } & $\mathrm{T}_{1 / 2}(\mathrm{hr})$ & $3.12 \pm 0.42$ & $5.01 \pm 0.59$ \\
\hline & $\mathrm{AUC}_{0-24 \mathrm{hr}}(\mathrm{ng} \cdot \mathrm{hr} / \mathrm{mL})$ & $367.1 \pm 77.9$ & $557.4 \pm 166.3$ \\
\hline & $\mathrm{AUC}_{\text {inf }}(\mathrm{ng} \cdot \mathrm{hr} / \mathrm{mL})$ & $368.1 \pm 78.4$ & $567.1 \pm 166.9$ \\
\hline & $\mathrm{CL}_{\mathrm{p}}(\mathrm{mL} / \mathrm{min} / \mathrm{kg})$ & $5.11 \pm 1.38$ & $3.79 \pm 1.47$ \\
\hline & $\mathrm{V}_{\mathrm{ss}}(\mathrm{mL} / \mathrm{kg})$ & $502.6 \pm 50.7$ & $988.2 \pm 410.9$ \\
\hline & $\mathrm{MRT}_{\text {inf }}(\mathrm{hr})$ & $1.84 \pm 0.45$ & $4.25 \pm 0.14$ \\
\hline \multirow{6}{*}{ Pitavastatin Lactone } & $\mathrm{T}_{\max }(\min )$ & $110.4 \pm 65.4$ & $180.1 \pm 34.4$ \\
\hline & $\mathrm{C}_{\max }(\mathrm{ng} / \mathrm{mL})$ & $12.6 \pm 2.2$ & $13.7 \pm 1.4$ \\
\hline & $\mathrm{T}_{1 / 2}(\mathrm{hr})$ & $4.50 \pm 0.37$ & $7.23 \pm 2.35$ \\
\hline & $\mathrm{AUC}_{0-24 \mathrm{hr}}(\mathrm{ng} \cdot \mathrm{hr} / \mathrm{mL})$ & $118.2 \pm 29.3$ & $186.0 \pm 24.8$ \\
\hline & $\mathrm{AUC}_{\text {inf }}(\mathrm{ng} \cdot \mathrm{hr} / \mathrm{mL})$ & $121.1 \pm 31.8$ & $218.7 \pm 19.0$ \\
\hline & $\mathrm{MRT}_{\text {inf }}(\mathrm{hr})$ & $7.29 \pm 0.61$ & $12.10 \pm 3.02$ \\
\hline
\end{tabular}

The pharmacokinetic parameters are given in Table I. The plasma concentration of pitavastatin under both conditions declined three-exponentially, and was below the limit of quantification $(0.5 \mathrm{ng} / \mathrm{mL})$ by $24 \mathrm{hr}$ after dosing. On the other hand, pitavastatin lactone was detected in two out of three dogs with the non-diverted bileflow even at $24 \mathrm{hr}$ after dosing.

The $\mathrm{T}_{1 / 2}$ for pitavastatin in the dogs with the diverted and non-diverted bile-flow was 3.12 and $5.01 \mathrm{hr}$, respectively. The $\mathrm{T}_{1 / 2}$ for pitavastatin was shortened to $62 \%$ by interrupting the enterohepatic circulation. The $\mathrm{AUC}_{0-24 \mathrm{hr}}, \mathrm{MRT}_{\mathrm{inf}}$, and $\mathrm{CL}_{\mathrm{p}}$ for pitavastatin was $367 \mathrm{ng}$ - $\mathrm{hr} / \mathrm{mL}, 1.84 \mathrm{hr}$, and $5.11 \mathrm{~mL} / \mathrm{min} / \mathrm{kg}$, respectively, in the diverted condition, and $557 \mathrm{ng} \cdot \mathrm{hr} / \mathrm{mL}, 4.25 \mathrm{hr}$, and $3.79 \mathrm{~mL} / \mathrm{min} / \mathrm{kg}$, respectively, in the non-diverted condition. The difference between the two conditions observed for $\mathrm{AUC}_{0-24 \mathrm{hr}}, \mathrm{MRT}_{\mathrm{inf}}$, and $\mathrm{CL}_{\mathrm{p}}$ was due to the alternation of the terminal phase.

Plasma concentrations of pitavastatin lactone in the diverted and non-diverted bile-flow conditions reached a maximum level of $12.6 \mathrm{ng} / \mathrm{mL}$ at about $110 \mathrm{~min}$ and 13.7 $\mathrm{ng} / \mathrm{mL}$ at about $180 \mathrm{~min}$, respectively, after dosing. The $\mathrm{T}_{1 / 2}$ for pitavastatin lactone was $4.50 \mathrm{hr}$ in the diverted condition, and $7.23 \mathrm{hr}$ in the non-diverted condition. The $\mathrm{AUC}_{0-24 \mathrm{hr}}$ for pitavastatin lactone was $118 \mathrm{ng} \cdot \mathrm{hr} / \mathrm{mL}$ in the diverted, and $186 \mathrm{ng} \cdot \mathrm{hr} / \mathrm{mL}$ in the non-diverted condition. The $\mathrm{T}_{1 / 2}$ and $\mathrm{AUC}_{0-24 \mathrm{hr}}$ values were reduced to $62 \%$ and $64 \%$, respectively, by interrupting the enterohepatic circulation.

\section{Biliary Excretion of Pitavastatin and its Lactone}

The cumulative biliary excretion of pitavastatin and its lactone after intravenous administration of pitavastatin in the dogs with the diverted bile-flow are shown in Fig. 3. The pharmacokinetic parameters are given in Table II. The percentage of pitavastatin excreted into bile was $46.0 \%$ of the dose by $2 \mathrm{hr}$ after dosing, and $56.1 \%$ at 24

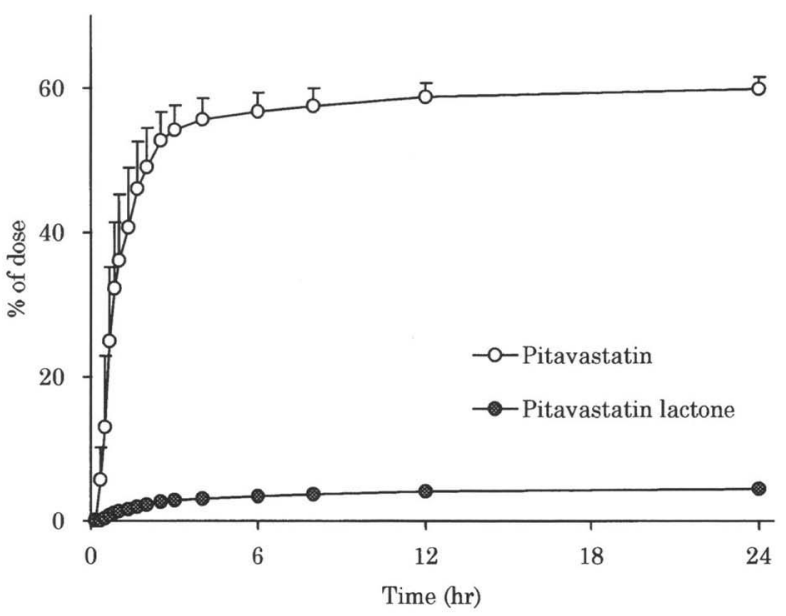

Fig. 3 Mean cumulative biliary excretion rate of pitavastatin and its lactone after intravenous administration of 0.1 $\mathrm{mg} / \mathrm{kg}$ of pitavastatin in chronic bile-duct cannulated dogs

Each point represents the mean and S.E. of three experiments.

hr. That of pitavastatin lactone excreted was $2.7 \%$ of the dose by $2 \mathrm{hr}$ after dosing and $4.2 \%$ at $24 \mathrm{hr}$. About $80 \%$ of the total biliary excretion of pitavastatin and its lactone occurred within $2 \mathrm{hr}$ after dosing. This may reflect reabsorption from the intestinal tract.

The $\mathrm{CL}_{\mathrm{b}}$ of pitavastatin and its lactone was 32.5 and $6.8 \mathrm{~mL} / \mathrm{min}$, respectively. The $\mathrm{CL}_{\mathrm{b}}$ of pitavastatin was about 4.8-fold greater than that of pitavastatin lactone. The cumulative biliary excretion of pitavastatin and its lactone in the non-diverted bile-flow can be estimated from eq. $3-4$, if the $\mathrm{CL}_{\mathrm{b}}$ value is not altered by the bileflow conditions. This estimated cumulative biliary excretion was $904 \mu \mathrm{g}$ for pitavastatin and $72 \mu \mathrm{g}$ for its lactone, representing $80.7 \%$ and $7.1 \%$ of the dose, respectively. 
Table II Biliary excretion and pharmacokinetic parameters of pitavastatin and its lactone after intravenous administration of 0.1 $\mathrm{mg} / \mathrm{kg}$ of pitavastatin in chronic bile-duct cannulated dogs

\begin{tabular}{clcc}
\hline \multirow{2}{*}{ Drug } & \multicolumn{1}{c}{ Parameters (unit) } & $\begin{array}{c}\text { Diverted bile-flow condition } \\
\text { Mean } \pm \text { S.E. }\end{array}$ & $\begin{array}{c}\text { Nondiverted bile-flow condition }{ }^{\text {a) }} \\
\text { Mean } \pm \text { S.E. }\end{array}$ \\
\hline \multirow{4}{*}{ Pitavastatin } & $\mathrm{X}_{\mathrm{b}}(\mu \mathrm{g})$ & $624.5 \pm 20.5$ & $904.1 \pm 119.9$ \\
& Biliary excretion rate $(\%$ of dose $)$ & $56.1 \pm 3.6$ & $80.7 \pm 9.2$ \\
& $\mathrm{CL}_{\mathrm{b}}(\mathrm{mL} / \mathrm{min})$ & $32.5 \pm 9.8$ & - \\
\hline \multirow{2}{*}{ Lactone } & $\mathrm{X}_{\mathrm{b}}(\mu \mathrm{g})$ & $43.2 \pm 2.3$ & $7.1 \pm 1.1$ \\
& Biliary excretion rate $(\%$ of dose $)$ & $4.2 \pm 0.2$ & - \\
\hline
\end{tabular}

a) : Biliary parameters for nondiverted bile flow were calculated from eqs. 3 and 4 .

This indicates that the enterohepatic circulation increased the total biliary excretion of pitavastatin and its lactone by about $46 \%$.

\section{Discussion}

In humans and laboratory animals except rodents, pitavastatin lactone, which is mutually converted to pitavastatin in the circulatory system, is the predominant metabolite. Therefore, the enterohepatic circulation of pitavastatin taking into consideration the contribution of its lactone was clarified pharmacokinetically by determining both forms of pitavastatin in the plasma and bile of chronic bile-duct cannulated dogs. All experiments in the cannulated dogs were performed under unanesthesia.

In the cannulated dogs with the diverted and nondiverted bile-flow, the plasma concentration time-curve of pitavastatin decreased three-exponentially after dosing. The enterohepatic circulation is a complex phenomenon involving several physiological steps, and affects the shape of the plasma concentration-time curve. In some cases, the terminal $T_{1 / 2}$ may increases. ${ }^{9,10)}$ However, when a drug is released by gallbladder contraction or excreted predominantly as the conjugate into the bile, the plasma concentration time-curve may shows a secondary rise. ${ }^{11,12)}$ In the case of pitavastatin, no secondary increase was observed. Instead, the terminal $\mathrm{T}_{1 / 2}$ of pitavastatin and its lactone were prolonged from 3.12 to $5.01 \mathrm{hr}$ and from 4.50 to $7.23 \mathrm{hr}$, respectively, by the enterohepatic circulation. In the diverted bile-flow condition, about $80 \%$ of total biliary excretion occurred in the first $2 \mathrm{hr}$ after dosing as pitavastatin and its lactone. This suggests that the rapid biliary excretion in the early stage contributed toward the prolongation of the terminal $\mathrm{T}_{1 / 2}$ for both forms of pitavastatin.

The $\mathrm{CL}_{\mathrm{b}}$ and biliary excretion rate of pitavastatin in the dogs with the diverted bile-flow were $32.5 \mathrm{~mL} / \mathrm{min} /$ $\mathrm{kg}$ and $56 \%$ of the dose, respectively, while for pitavastatin lactone these values were $6.8 \mathrm{~mL} / \mathrm{min} / \mathrm{kg}$ and $4 \%$. We previously reported that the urinary excretion of both forms of pitavastatin in normal dogs after intravenous administration was about $0 \%,{ }^{4)}$ These find- ings suggest that about $60 \%$ of the dose was excreted into the bile as a recirculating fraction during one enterohepatic cycle, a negligible amount was excreted via urine, and the remainder, about $40 \%$, was eliminated via biotransformation.

The contribution of the enterohepatic circulation is commonly estimated from the AUC values in the diverted and non-diverted bile-flow conditions. However, in the case of pitavastatin taking its lactone into consideration, the AUC value is not an adequate parameter because the biliary excretion of each drug depends on the respective $\mathrm{CL}_{\mathrm{b}}$. Accordingly, the cumulative biliary excretion of pitavastatin and its lactone in the non-diverted condition were estimated from eqs. $3-4$ using the individual $\mathrm{AUC}_{\text {(NONDIVERT) }}$ and $\mathrm{CL}_{\mathrm{b}}$ values. The estimated cumulative biliary excretion increased by $45 \%$ for pitavastatin and $67 \%$ for its lactone, compared with the value in the diverted condition. These results suggest that the increase in the total cumulative biliary excretion of pitavastatin and its lactone, about 1.5-fold, shows the actual amount reabsorbed and recycled in the overall enterohepatic circulation.

In this study, we calculated that the $\mathrm{CL}_{\mathrm{b}}$ of pitavastatin was about 4.8-fold greater than that of pitavastatin lactone. This difference could be due to the extent of biliary excretion through the bile canaliculi. Studies have been conducted on substrates for a canalicular multispecific organic anion transporter (cMOAT) by comparing normal rats and Eisai hyperbilirubinemic rats (EHBR), in which this transport system is defective. It has been reported that the biliary excretion of pravastatin, which has an anionic charge in the carboxylate form, was mainly mediated by cMOAT in rats. ${ }^{13)}$ The metabolites of irinotecan, which have the carboxylate form, were also a good substrate for cMOAT. ${ }^{14)}$ The excretion, however, of irinotecan and its active metabolite, which have the lactone form, into bile in rats is restricted because these forms have less affinity to cMOAT. The close resemblance of these carboxylate structures, indicates the involvement of a transporter, which has a similar function to cMOAT, for pitavastatin in dogs. On the other hand, pitavastatin lactone, which has no anionic structure, may 
be a poor substrate for this transporter.

\section{Conclusions}

The objective of this study was to ascertain the enterohepatic circulation of pitavastatin and its lactone in chronic bile-duct cannulated dogs

1. The enterohepatic circulation contributed toward the prolongation of the terminal $\mathrm{T}_{1 / 2}$ for both forms of pitavastatin.

2. The $\mathrm{CL}_{\mathrm{b}}$ value of pitavastatin was about 4.8 -fold that of its lactone form.

3. In the dogs with the diverted bile-flow, about 56.1 $\%$ and $4.2 \%$ of the dose were excreted as pitavastatin and its lactone, respectively, into the bile. The biliary excretion of pitavastatin and its lactone in the non-diverted bile-flow was estimated to be about $80.7 \%$ and $7.1 \%$ of the dose, respectively. This finding suggests that the enterohepatic circulation increase the total biliary excretion by $46 \%$

Acknowledgments : We thank Yumiko Hirose, Miyoko Aoki, Midori Sakai, and Masako Isuge for excellent technical assistance.

\section{References}

1) Aoki T., Nishimura H., Nakagawa S., Kojima J., Suzuki H., Tamaki T., Wada Y., Yokoo N., Sato F., Kimata H., Kitahara M., Toyoda K., Sakashita M. and Saito Y.: Pharmacological profile of a novel synthetic inhibitor of 3 hydroxy-3-methylglutaryl-coenzme A reductase. $A r$ zneim.-Forsch./Drug Res., 47 (8): 904-909 (1997).

2) Suzuki H., Aoki T., Tamaki T., Sato F., Kitahara M. and Saita Y.: Hypolipidemic effect of NK-104, a potent HMG$\mathrm{CoA}$ reductase inhibitor, in guinea pigs. Atherosclerosis, 146: 259-270 (1999).

3) Nakaya N., Kojima J., Kimata H., Kuwahata R. and Narusima H.: NK-104, efficacy and tolerance of a new synthetic HMG-CoA reductase inhibitor in hypercholesterolemic volunteers. XIIth International Symposium on Drug Affecting Lipid Metabolism (Abstructs) Houston, USA, 137, (1995).

4) Fujino H., Kojima J., Yamada Y., Kanda H. and Kimata H.: Studies on the metabolic fate of NK-104, a new inhibitor of
HMG-CoA reductase (4): Interspecies variation in laboratory animals and humans. Xenobio. Metabol. Dispos., 14(2): 79-91 (1999).

5) Kojima J., Fujino H., Abe H., Yoshimura M., Kanda H. and Kimata H.: Identification of metabolites of NK-104, an HMG-CoA reductase inhibitor, in rat, rabbit and dog bile. Biol. Pharm. Bull., 22 (2): 142-150 (1999).

6) Kimata H., Fujino H., Koide T., Yamada Y., Tsunenari Y. Yonemitsu M. and Yanagawa Y.: Studies on the metabolic fate of $\mathrm{NK}-104$, a new inhibitor of $\mathrm{HMG}-\mathrm{CoA}$ reductase (1): Absorption, distribution, metabolism and excretion in rats. Xenobio. Metabol. Dispos., 13(5): 484-498 (1998).

7) Kojima J., Fujino H., Yosimura M., Morikawa H.. and Kimata H.: Simultaneous determination of NK-104 and its lactone in biological samples by column-switching highperformance liquid chromatography and ultraviolet detection. J. Chromatogr. (B), 724: 173-180 (1999).

8) Yamaoka K., Nakagawa T. and Uno T.: Statistical moments in pharmacokinetics. J. Pharmacokinet. Biopharm., 6 (6): 547-558 (1978)

9) Cotler S., Chen S., Macasieb T. and Colburn W. A.: Effect of route of administration and biliary excretion on the pharmacokinetics of isotretinon in the dog. Drug Metab. Dispos., 12 (2): 143-147 (1984).

10) Uemura Y., Tanaka S., Ida S. and Yuzuriha T.: Pharmacokinetic study of loprinone hydrochloride, a new cardiotonic agent, in beagle dogs. J. Pharm. Pharmacol., 45: 1077-1081 (1993).

11) Priymenko N., Garnier F., Ferre J-P., Delatour P. and Toutain P-L.: Enantioselectivity of the enterohepatic recycling of carprofen in the dog. Drug Metab. Dispos., 26(2): 170-176 (1998).

12) Ouellet D. M. C. and Pollack G. M.: Biliary excretion and enterohepatic recirculation of morphine-3-glucuronide in rats. Drug Metab. Dispos., 23 (4): 478-484 (1995).

13) Yamazaki M., Akiyama S., Niinuma K., Nishigaki R. and Sugiyama Y.: Biliary excretion of pravastatin in rats: Contribution of the excretion pathway mediated by canalicular multispecific organic anion transporter (cMOAT). Drug Metab. Dispos., 25 (10): 1123-1129 (1997)

14) Chu X-Y., Kato Y., Niinuma K., Sudo K., Hakusui H. and Sugiyama Y.,:Multispecific organic anion transporter is responsible for the biliary excretion of the camptothecin derivative irinotecan and its metabolites in rats. J. Pharmacol. Exp. Ther., 281(1): 304-314 (1997). 